\title{
Effectiveness of Humidification with Heat and Moisture Exchanger-booster in Tracheostomized Patients
}

\author{
Isabel Gonzalez, Pilar Jimenez, Jorge Valdivia, Antonio Esquinas ${ }^{1}$ \\ Intensive Care Unit, Complejo Hospitalario de León, León, 'Intensive Care Unit, Hospital Morales Meseguer, Murcia, Spain
}

\section{Abstract}

Background: The two most commonly used types of humidifiers are heated humidifiers and heat and moisture exchange humidifiers. Heated humidifiers provide adequate temperature and humidity without affecting the respiratory pattern, but overdose can cause high temperatures and humidity resulting in condensation, which increases the risk of bacteria in the circuit. These devices are expensive. Heat and moisture exchanger filter is a new concept of humidification, increasing the moisture content in inspired gases. Aims: This study aims to determine the effectiveness of the heat and moisture exchanger (HME)-Booster system to humidify inspired air in patients under mechanical ventilation. Materials and Methods: We evaluated the humidification provided by 10 HME-Booster for tracheostomized patients under mechanical ventilation using Servo I respirators, belonging to the Maquet company and Evita 4. Results: There was an increase in the inspired air humidity after $1 \mathrm{~h}$ with the humidifier. Conclusion: The HME-Booster combines the advantages of heat and moisture exchange minimizing the negatives. It increases the amount of moisture in inspired gas in mechanically ventilated tracheostomized patients. It is easy and safe to use. The type of ventilator used has no influence on the result.

Keywords: Booster, humidification, mechanical ventilation, self-regulating, tracheotomy

\section{INTRODUCTION}

The upper airway plays a very important role as a barrier to protect the lung, acting as a filter, humidifying and conditioning inspired air before reaching the trachea, preventing dehydration of the secretions, and facilitating mobilization. ${ }^{[1,2]}$ The nose and oropharynx are responsible for most of this process. In tracheotomy patients, this route is bypassed, leading to the entry of cold, dry air directly into the trachea form. Due to this, during mechanical ventilation, where protection exerted by the upper airway is abolished by the presence of an endotracheal tube, inspired gases should be reheated and some moisture added. ${ }^{[3]}$

The two most commonly used types of humidifiers are heated humidifiers and heat and moisture exchange humidifiers. Heated humidifiers provide adequate temperature and humidity without affecting the respiratory pattern, but overdose can cause high temperatures and humidity resulting in condensation, which increases the risk of bacteria in the circuit. These devices are expensive.

Heat and moisture exchangers (HMEs) are efficient, prevent condensation in the circuit and are also less expensive than the

\begin{tabular}{|l|l|}
\hline \multicolumn{3}{|c|}{ Access this article online } \\
\hline Quick Response Code: & Website: \\
& www.ijccm.org \\
& \\
\end{tabular}

other. Sometimes, HMEs cannot provide an adequate degree of heat and humidity during mechanical ventilation with high flow or with low body temperature or when exhaled air is lost. Furthermore, because the HME devices increase the work of breathing, we used with caution during ventilation with pressure support, for weak or fatigued patients with respiratory failure. Nakagawa et al. suggest that in patients with thick or copious secretions, it is better to use the heated humidifier instead of the HME. ${ }^{[4]}$

Heat and moisture exchanger filter is a new concept of humidification, increasing the moisture content in inspired gases. Using a small conventional Booster located between the humidifier and patient, which is small, and provided with a self-regulator covered by a membrane in the respiratory circuit electric heater. This is made of membranous Gore-Tex material that prevents the passage of water.

Address for correspondence: Dr. Isabel Gonzalez, Complejo Hospitalario de León, León, Spain. E-mail: ucisabel@yahoo.es

This is an open access article distributed under the terms of the Creative Commons Attribution-NonCommercial-ShareAlike 3.0 License, which allows others to remix, tweak, and build upon the work non-commercially, as long as the author is credited and the new creations are licensed under the identical terms.

For reprints contact: reprints@medknow.com

How to cite this article: Gonzalez I, Jimenez P, Valdivia J, Esquinas A. Effectiveness of humidification with heat and moisture exchanger-booster in tracheostomized patients. Indian J Crit Care Med 2017;21:528-30. 
The HME-Booster is a T-shaped device equipped with hydrophobic membrane, allowing water to pass only when it evaporates.

The purified water saturates the hydrophobic membrane. The water is then heated to the vaporization point and passes through the membrane and enters the delivered gas stream. Water enters the HME-Booster by way of a Luer-Lok connection. The moisture in the saturated membrane is heated by the point temperature control element. The amount of water added to the inspired air depends on the moisture gradient across one side to the other side, this regulates the amount of water being added self-regulating system [Figure 1]. ${ }^{[5]}$

\section{Objectives}

The aim of this study is to determine the effectiveness of the HME-Booster system to humidify inspired air in patients under mechanical ventilation. We used tracheostomized patients due to difficulty weaning patients ventilated with mechanical ventilation.

\section{Materials and Methods}

We evaluated the humidification provided by $10 \mathrm{HME}-$ Booster for tracheostomized patients under mechanical ventilation using Servo I respirators, belonging to the Maquet Company and Evita 4.

All patients were tracheostomized by difficulty of disconnection from the ventilator: three patients with diagnostic of pneumonia, one patient with sepsis and previous diagnostic of chronic obstructive pulmonary disease, and six with neurological disease. Half of all patients had thick secretions. We have measured the minimum absolute humidity before and after $1 \mathrm{~h}$ with the humidifier. All patients were normothermic [Table 1].

We measured the minimum absolute humidity, defined as moisture in a unit volume of gas at a certain temperature $\left(\mathrm{g} / \mathrm{m}^{3}\right.$ or $\left.\mathrm{mg} / \mathrm{L}\right)$.

$44 \mathrm{mg} / \mathrm{L}$ at $37^{\circ} \mathrm{C}$ is considered a normal value.

To determine failure to obtain optimal humidification, we use the scale:

Secretion score:

1. No secretions in suction

2. Watery discharge, the suction catheter remains clean

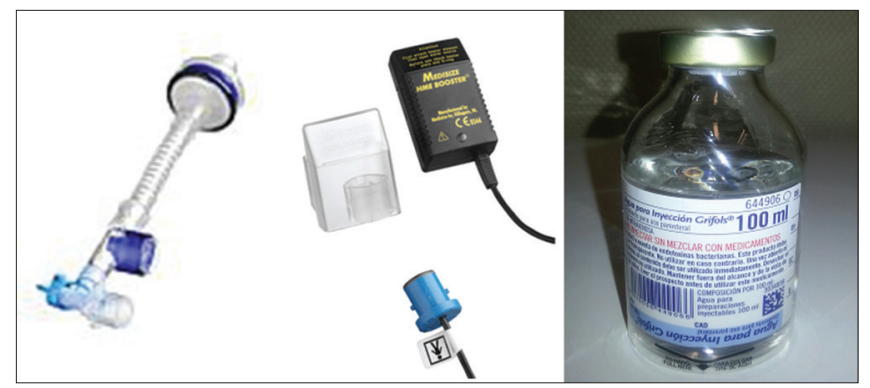

Figure 1: Heat and moisture exchanger Booster components
3. Normal secretions and some secretions remain inside the suction catheter and removed using suction with water

4. Thick secretions and secretions remain within the suction catheter and not removed using suctioning with water.

We define humidification failure for either of these situations:

1. Inadequate humidification, secretions Grade 2 for two consecutive hours

2. Over-humidification, secretions Grade 2, needing more than four aspirations per hour for two consecutive hours.

Measures were calculated according to a hygrometer with a temperature sensor and a humidity sensor located between the patient and the humidifier (PCS 10 Medisize).

Data were analyzed by way of the computer program PC Laboratory 200SE, provided by Medisize.

\section{RESULTS}

There was an increase in the inspired air humidity after $1 \mathrm{~h}$ with the humidifier.

In all patients, the HME-Booster provides humidification $>37 \mathrm{mg} \mathrm{H} \mathrm{H}_{2} \mathrm{O} / \mathrm{L}$ [Graph 1].

During use, no failure was observed in the humidification or obstruction of the endotracheal tube. Neither we observed

\section{Table 1: Conditions patients}

\begin{tabular}{lllcl}
\hline Sex & Age & Diagnosis & APACHE II & $\begin{array}{l}\text { Mecanical } \\
\text { ventilation }\end{array}$ \\
\hline Male & 61 & CVA & 22 & Evita 4 \\
Female & 54 & Hemorrhagic stroke & 18 & Maquet \\
Male & 75 & Sepsis & 28 & Evita XL \\
Male & 23 & Severe trauma & 12 & Evita XL \\
Male & 81 & CAP/ARDS & 25 & Maquet \\
Female & 68 & Spinal cord injury & 10 & Evita 4 \\
Male & 49 & Head trauma & 15 & Maquet \\
Female & 52 & Hemorrhagic stroke & 17 & Evita XL \\
Male & 71 & COPD & 23 & Evita 4 \\
Male & 69 & CAP & 20 & Evita XL \\
\hline
\end{tabular}

COPD: Chronic obstructive pulmonary disease; ARDS: Acute respiratory distress syndrome; CAP: Community-acquired pneumonia; CVA: Cerebrovascular accident; APACHE: Acute Physiology and Chronic Health Evaluation

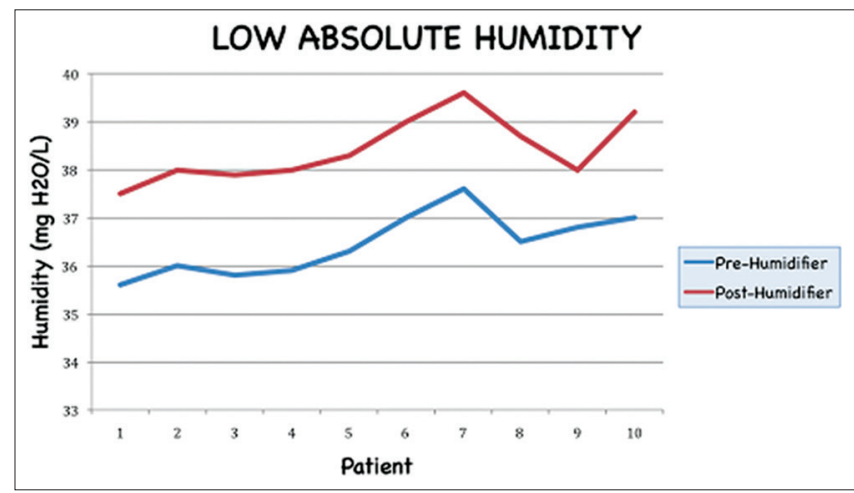

Graph 1: Moisture results 
over-humidification, for these reasons, we affirm that it is safe.

\section{Discussion}

There are few publications about the HME humidification system-Booster in tracheostomized patients, and we have found, during the search in PubMed, no study on the HME-Booster system in critically ill patients with tracheostomy and mechanical ventilation. The optimum humidity in the inspired gas in patients in Intensive Care Units has not been well established, but the data suggest and maintain it between 23 and $33 \mathrm{mg} / \mathrm{H}_{2} \mathrm{O} / \mathrm{L}$.

In an essay published by Menegueti et al..$^{[1]}$ heated humidifiers and HME differ very little regarding effectiveness, this technology incurs low direct cost. Like us, they conclude that this system is effective, simple, and low cost.

The Cochrane review of heated humidification versus HMEs concludes that there is little evidence of an overall difference between HMEs and heated humidification. ${ }^{[6]}$ They included 33 trials with 2833 participants, there was no overall effect on artificial airway occlusion, mortality, pneumonia, or respiratory complications; however, minute ventilation was increased when HMEs were compared with heated humidification. Another study published in 1998 by Thomachot et al. ${ }^{[7]}$ shows that the HME and Aerodyne system were equally effective in preserving heat and humidity in patients with tracheotomy; however, in this case, the patients were breathing spontaneously.

Keeping in mind the conclusions in his study, Chikata et al ${ }^{[3]}$ of 2013: when supplemental oxygen is used, humidity decreases and insufficient levels with HME are achieved. Considering our results, it seems appropriate to use an active humidification system, to achieve adequate tracheotomy moisture in patients with invasive mechanical ventilation.

Our study clearly demonstrates that the HME-Booster humidification system is effective to keep moisture in these patients, which is the goal of the study.

The limitations of the study were that we did not analyze the effects of HME-Booster in respiratory function and did not study the microbiological contamination of the ventilator circuit. This system was not compared with any other humidifiers. Although we did not evaluate the economic aspect, keep in mind that this humidifier is relatively inexpensive.

\section{Conclusions}

1. The HME-Booster combines the advantages of the heat and moisture exchange humidifiers minimizing the negatives

2. It increases the amount of moisture in inspired gas in mechanically ventilated tracheostomized patients

3. It is easy and safe to use

4. The type of ventilator used has no influence on the result.

\section{Financial support and sponsorship}

Nil.

\section{Conflicts of interest}

Study performed by material supplied by the Company Medisize.

\section{RefEREnCes}

1. Menegueti MG, Auxiliadora-Martins M, Nunes AA. Cost-effectiveness analysis of heat and moisture exchangers in mechanically ventilated critically Ill patients. Anesth Pain Med 2016;6:e32602.

2. Suzukawa M, Usuda Y. The effects on sputum characteristics of combining an unheated humidifier with a heat and moisture exchanging filter. Respir Care 1989;34:976-84.

3. Chikata Y, Oto J, Onodera M, Nishimura M. Humidification performance of humidifying devices for tracheostomized patients with spontaneous breathing: A bench study. Respir Care 2013;58:1442-8.

4. Nakagawa NK, Macchione M, Petrolino HM, Guimarães ET, King M, Saldiva PH, et al. Effects of a heat and moisture exchanger and a heated humidifier on respiratory mucus in patients undergoing mechanical ventilation. Crit Care Med 2000;28:312-7.

5. Pelosi P, Severgnini P, Selmo G, Corradini M, Chiaranda M, Novario R, et al. In vitro evaluation of an active heat-and-moisture exchanger: The Hygrovent Gold. Respir Care 2010;55:460-6.

6. Kelly M, Gillies D, Todd DA, Lockwood C. Heated humidification versus heat and moisture exchangers for ventilated adults and children. Cochrane Database Syst Rev 2010;14:CD004711.

7. Thomachot L, Viviand X, Arnaud S, Vialet R, Albanese J, Martin C. Preservation of humidity and heat of respiratory gases in spontaneously breathing, tracheostomized patients. Acta Anaesthesiol Scand 1998;42:841-4. 